\title{
A FUNÇÃO SOCIAL DA PROPRIEDADE E O LICENCIAMENTO COMPULSÓRIO DE MEDICAMENTOS NO BRASIL
}

\section{SOCIAL FUNCTION OF THE PROPERTY AND COMPULSORY LICENSING OF DRUGS IN BRAZIL}

\author{
${ }^{1}$ Wallace Leite Nogueira \\ 2 Victor Hugo Tejerina Velázquez
}

\section{RESUMO}

A propriedade intelectual é protegida no Brasil por dispositivo contido na Constituição Federal, na Legislação ordinária, sendo o Brasil ainda signatário do acordo TRIPS. A propriedade é protegida de forma relativa, pois a propriedade deverá atender à função social. Uma das formas de viabilizar a observância à função social da propriedade é o licenciamento compulsório, medida excepcional e deve atender requisitos legais. No Brasil houve o licenciamento compulsório do medicamento Efavirenz, retroviral destinado a população acometida como vírus da AIDS, de forma a atender o programa nacional de combate a AIDS.

Palavras-chave: Função Social da Propriedade, Licenciamento Compulsório, Medicamentos, AIDS.

\begin{abstract}
Intellectual property is protected in Brazil device contained in the Federal Constitution, the common law, and Brazil also signed the TRIPS agreement. The property is protected in a relative terms, because the property must meet the social function. A way to facilitate compliance with the social function of property is compulsory licensing, exceptional measure and should meet legal requirements. In Brazil there was the compulsory licensing of Efavirenz drug, retroviral for the infected population with AIDS virus, in order to meet the national program to combat AIDS.
\end{abstract}

Keywords: Social Function of Property, Compulsory Licensing, Drugs, AIDS.

\footnotetext{
${ }^{1}$ Mestrando em Direito pela Universidade Metodista de Piracicaba - UNIMEP, São Paulo, (Brasil). Advogado. E-mail: wallace.nogueira@ aasp.org.br

${ }^{2}$ Doutor em Direito pela Pontifícia Universidade Católica - PUC, São Paulo, (Brasil). Editor de Cadernos de Direito. Professor, Fundador, Ex-Coordenador do Programa de Pós-Graduação em Direito da Universidade Metodista de Piracicaba - UNIMEP. Coordenador do NEDAEPI. Professor horista do Centro Universitário Adventista de São Paulo - UNASP. E-mail: vhtejerina@yahoo.com.br
} 


\section{INTRODUÇÃO}

A Proteção ao Direito de propriedade intelectual está positivada em nosso ordenamento jurídico na Constituição Federal e legislação infraconstitucional. Além disso, o Brasil aderiu ao TRIPS. Todavia esta proteção que o Estado empresta ao detentor da propriedade intelectual não é absoluta, pois esbarra na função social que a propriedade deve ter. Ainda que esteja prevista a proteção da propriedade privada em âmbito constitucional, este direito deve ser sopesado com os demais, notadamente o direito a vida, a saúde e a dignidade da pessoa humana.

A Lei de Propriedade Industrial (Lei Federal nº 9.279, de 14 de maio de 1996) trouxe o instituto o licenciamento compulsório, e no mesmo ano houve a publicação da Lei Federal $\mathrm{n}^{\mathrm{o}}$ 9.313/96, que tornou obrigatória a distribuição de medicamentos antirretrovirais (ARVs) pelo sistema público de saúde.

O objetivo é demonstrar que ainda que haja legislação protetiva as criações humanas, tanto no Brasil como fora dele, aqui há um mecanismo de exceção desta proteção que é o licenciamento compulsório, que foi aplicado ao medicamento Efavirenz, cuja patente foi registrada para a empresa Merck, Sharp \& Dohme, tendo este caso grande repercussão na mídia nacional e estrangeira.

A linha de pesquisa utilizada para este estudo foi crítico metodológica onde se buscou a análise do aspecto jurídico do direito de propriedade intelectual e contou com a análise sistemática dos dispositivos constitucionais constantes do artigo 5, incisos XXII e XXIII, artigo 170, inciso III, Lei Federal $n^{\circ}$ 9.279, e 14 de maio de 1996, Leis Ordinárias, princípios constantes do acordo TRIPs ${ }^{3}$, bem como levantamento bibliográfico sobre a problemática do tema e foi adotada a vertente jurídico sociológica para o desenvolvimento do tema.

\section{DESENVOLVIMENTO}

O ser humano desde os primórdios da civilização desenvolve técnicas para otimizar atividades diversas, desde as mais corriqueiras até a consecução de objetivos mais complexos.

\footnotetext{
3 Agreement on Trade-Related Aspects of Intellectual Property Rights - em português: Acordo sobre Aspectos dos Direitos de Propriedade Intelectual Relacionados ao Comércio - é um tratado Internacional, integrante do conjunto de acordos assinados em 1994 que encerrou a Rodada Uruguai e criou a Organização Mundial do Comércio.
} 
Quando o ser humano cria algo novo, que não existia antes pode ser considerado invenção. Invenção, no conceito de Fábio Ulhôa Coelho "é o ato original do gênio humano" (COELHO, p. 74, 1997). Assim, desde os primeiros utensílios de pedra que datam 2.600.000 a.C. (CHALLONER, 2010, p. 22) o ser humano passou a interagir no seu meio ambiente e começou a se diferenciar das demais espécies do planeta. Assim as ideias e invenções foram fundamentais para a criação das civilizações.

A invenção e a tecnologia passaram a ter maior relevância na economia capitalista, onde a concorrência é acirrada e foram desenvolvidos novos produtos, métodos e processos, bem como começava-se a angariar um público consumidor, levando os empreendedores a criar sinais e marcas para distinguir-se dos demais no mercado. Isso justifica a necessidade dos empreendedores em buscar a proteção Estatal como forma de resguardar seus bens incorpóreos, bem como a exclusividade.

Para se ter compreensão da proteção a propriedade intelectual é preciso absorver que o sentimento de propriedade é inerente do ser humano, inclusive como forma de sua própria subsistência. Este conceito é fundado sob a concepção filosófica do Direito Natural, mas sua forma de exercício é limitada pela atuação Estatal. Como manifestação do surgimento da propriedade intelectual Patrícia Aurélia Del Nero assim explica: “a propriedade, nas formações sociais humanas, abrange um amplo leque de alternativas e passa a incorporar tanto bens materiais e imateriais quanto contemporaneamente, os próprios processos e meios para sua concepção e produção" (DEL NERO, 1998, p. 31).

$\mathrm{Na}$ legislação nacional temos a proteção da propriedade intelectual, de forma relativa, na medida em que nenhum direito é absoluto. Ademais é fundamental observar que a propriedade tem que exercer uma função social não podendo ser absoluta e oponível contra todos de forma a inviabilizar que a coletividade possa usufruir dos benefícios da invenção.

Assim, a função social da propriedade não é apenas um dogma, mas uma norma a ser observada, de eficácia plena. Cumpre ressaltar que a função social da propriedade tem inspiração na doutrina social da igreja, representada nas encíclicas Mater et Magistra, Populorum Progressio, onde a propriedade destina-se a função de servir de instrumento para criação de bens necessários à subsistência de toda humanidade, e também nas encíclicas Rerum Novarum e Quadragésimo Ano, onde a propriedade deveria ser menos individualista, de forma a ser relativa sendo uma espécie de hipoteca oculta em favor da coletividade (VIZZOTTO, 2010, p. 58). 
Como forma da atuação Estatal sobre o direito de propriedade, a Constituição Federal traz o direito à mesma no texto do artigo $5^{\mathrm{O}}$, inciso XXII, mas este não é absoluto e está condicionado a sua função social, nos termos do inciso XXIII. E não é somente nestes dispositivos que existe a atuação Estatal, havendo também a previsão na atividade econômica do Estado, artigo 170, inciso III, que também exige a observância do princípio da função social da propriedade. José Afonso da Silva posiciona-se no sentido de que mesmo que a propriedade esteja prevista nos direitos individuais, não poderá ser considerado um direito individual puro na medida em que os princípios da ordem econômica são preordenados à vista da realização de seu fim: "assegurar a todos existência digna, conforme os ditames da justiça social" (SILVA, 2000, p. 273-274).

Nenhum direito no ordenamento jurídico brasileiro é absoluto. O mesmo se diga ao direito de propriedade, sendo também um direito relativo e sujeito a ponderação (ROTHENBURG, 2014, p. 125) bem como às normas de desconsideração da propriedade (artigo 231, $\S 6^{\circ}$ e art. 68 ADCT, da Constituição Federal).

Assim, além de visualizarmos o direito a propriedade como relativo, o mesmo deve ser analisado sob o prisma do princípio da dignidade da pessoa humana, princípio este norteador das relações jurídicas, eis que sequer demandam da positivação Estatal, de forma a materializar o objetivo republicano.

De forma similar opera o princípio da função social da propriedade na medida em que limita o direito de propriedade, consubstanciando-se em um limite negativo aos direitos do proprietário, mas deve ter um alcance mais amplo, como o "poder de dar ao objeto da propriedade a certo objetivo" (COMPARATO, 1986, p. 75).

Assim, há de se concluir os dois espectros do direito à propriedade. O positivo, onde o Estado busca resguardar o direito de propriedade ao seu detentor, disponibilizando ao mesmo os instrumentos jurídicos para esta proteção e o negativo que veda a utilização nociva à sociedade (ZANIN NETO, VELAZQUEZ, 2012, p. 250). Em qualquer das hipóteses, nunca poderá se deixar de observar o interesse público. Manoel Gonçalves Ferreira Filho destaca que a Constituição não nega a exclusividade do direito do dono, mas a condiciona ao bem-estar geral, tendo o legislador constituinte "uma concepção tomista de que o proprietário é um procurador da comunidade para a gestão de bens destinados a servir a todos, embora não pertençam a todos" (FERREIRA FILHO, 1990, p. 302).

O direito de propriedade objeto do presente estudo diz respeito a propriedade de inventos, marcas, indústrias e nomes de empresas, ou seja propriedade sobre bens incorpóreos, 
previsto no artigo $5^{\circ}$, inciso XXIX da Constituição Federal, bem como na Lei Federal $\mathrm{n}^{\circ}$ 9.279, de 14 de maio de 1996, bem como acordos internacionais como a Convenção de Paris e o TRIPs, do qual o Brasil é signatário. O privilégio é um dos direitos assegurados no que diz respeito a invenção industrial, visando assegurar ao inventor o direito a obtenção da patente, que lhe garanta a propriedade do invento e o direito a exclusividade. Este privilégio, todavia, é temporário, concedendo o mínimo de 10 e máximo de 20 anos para a invenção, e o mínimo de 7 (sete) e máximo de 15 (quinze) anos para modelo de utilidade (objeto prático suscetível de aplicação industrial, como nova forma ou disposição que resulte melhoria funcional no seu uso ou na sua fabricação).

Merece ser esclarecido que a legislação não visa apenas assegurar direitos a seu detentor, mas criar obrigação ao mesmo para o exercício de seu direito, como, por exemplo, após concedida a licença sob determinado produto, o mesmo deverá ser colocado em funcionamento (ou produção) pelo inventor ou terceiro em até 03 (três) anos de sua concessão. Assim, caso o inventor ou terceiro que tenha a licença para colocar em funcionamento não o faça, poderá haver o licenciamento compulsório, que iremos tratar adiante.

Assim, a legislação pátria nos trouxe a Lei de Propriedade Industrial que visa a proteção das invenções a fim de que outras pessoas não se beneficiem sem a devida contrapartida do criador, mas também trouxe a possibilidade de exceção desta proteção quando houver relevante interesse público, através do licenciamento compulsório.

Vale observar que antes da promulgação da Lei de Propriedade Industrial no Brasil, havia impedimento a concessão da patente, que era fundamentado com base no fato de quem uma descoberta de medicamento diz respeito ao interesse público, podendo qualquer pessoa fabricar os medicamentos e, com isso, beneficiar o consumidor brasileiro.

Todavia, houve uma intensa pressão dos grandes grupos da indústria farmacêutica norte americana sobre os políticos brasileiros, no sentido de que era necessária a edição de uma legislação protetora dos inventos de fármacos, na medida em que era a única forma de fomentar os investimentos para pesquisa, desenvolvimento e inovação, que seriam custeados com o pagamento de royalties, e iriam beneficiar o público consumidor. Assim, foi elaborada, editada e promulgada a Lei Federal n ${ }^{\circ}$ 9.279, de 14 de maio de 1996 - Lei de Propriedade Industrial.

Com a Lei de Propriedade Intelectual, inaugurou-se a possibilidade de registro de patente de medicamentos, modificando o cenário anterior e, agora limitando as hipóteses de 
interesse público. Assim, a nova Lei trouxe uma "válvula de segurança" que é a possibilidade do licenciamento compulsório, aplicado nas hipóteses previstas na legislação.

Como lembrado em outra oportunidade:

Não se pode olvidar que "o processo de descoberta e desenvolvimento de novos medicamentos é muito complexo e de alto risco", segundo MONEDERO ${ }^{4}$, pois envolve investimentos em pesquisas e desenvolvimento de novos medicamentos, processos de obtenção e conformação do produto para venda.

Afirma ainda o supracitado autor que “(...) desde a concepção de uma ideia até a chegada de um medicamento ao mercado, dura entre 7 e 10 anos", segundo sua visão, tal panorama de investimentos fundamentaria a existência de um regime de concessão de privilégios de invenção, objetivando o retorno do capital investido em $\mathrm{P} \& \mathrm{D}$, bem como aos lucros da atividade econômica.

As empresas farmacêuticas, sejam nas rodadas de negociações internacionais ou tratativas para fornecimento de medicamentos para países em desenvolvimento, indicam que o licenciamento compulsório constitui um entrave aos investimentos em $\mathrm{P} \& \mathrm{D}^{5}$, uma vez que as multinacionais do setor farmacêutico, em razão dos vultuosos gastos para o desenvolvimento de fármacos teriam no sistema patentário rígido uma forma eficaz de retribuição dos valores dispendidos até a obtenção e comercialização do produto. E que o prazo de 20 (vinte) anos para a exploração do bem intangível patenteado seria um incentivo para os investimentos em P\&D. (TEJERINA-VELÁZQUEZ, Victor Hugo; COLLA DE OLIVEIRA, Michele Cristina Souza, 2016, p. 71-72)

Antes, porém, de adentrarmos no licenciamento compulsório, é preciso traçar os limites da regulação ao direito de propriedade intelectual no Brasil. A proteção Estatal ao direito de propriedade intelectual além de estar expressamente Constituição Federal traz em seu artigo $5^{\circ}$, inciso XXIX e na Lei Federal $\mathrm{n}^{\circ}$ 9.279, de 14 de maio de 1996, também encontra sustentáculo em acordos como a Convenção de Paris $^{6}$ e o TRIPS $^{7}$ (Acordo sobre Aspectos dos

\footnotetext{
${ }^{4}$ MONEDERO, Emilio Diez. A biotecnologia na indústria farmacêutica. (196-203) In: CASABONA, Carlos Maria Romeo. Biotecnologia, Direito e Bioética: perspectivas em Direito Comparado. Belo Horizonte: Del Rey e PUC Minas, 2002. p. 196.

${ }^{5}$ CAVALHEIRO, Rodrigo da Costa Ratto. O monopólio e as multinacionais farmacêuticas. Itu: Ottoni Editora, 2006.

${ }^{6}$ A Convenção de Paris é o primeiro acordo internacional relativo à propriedade intelectual, firmado em Paris, no ano de 1883 e continua em vigor com a versão de Estocolmo, coexistindo como TRIPS.

${ }^{7}$ O TRIPs, em inglês: ADPIC - TRIPS - Trade - Related Aspects of Intellectual Property Rights, é um tratado Internacional, integrante do conjunto de acordos assinados em1994 que encerrou a Rodada do Uruguai, sendo criada nesta oportunidade a Organização Mundial do Comércio. Assim, em eventual violação de dispositivo no acordo TRIPs o país poderá sofrer ações da O.M.C. além de sanções e embargos comerciais do país que teve os direitos de propriedade intelectual violados.
} 
Direitos de Propriedade Intelectual Relacionados ao Comércio), tratado do qual o Brasil é signatário.

A perquirição da delimitação das questões políticas, econômicas e sociais que envolvem a composição ou a formação dos preços dos medicamentos no Brasil é de suma importância para a compreensão dos efeitos dos direitos de propriedade intelectual sobre a efetivação dos direitos fundamentais sociais, em especial, utiliza-se como mote, o direito à saúde pública e a utilização do mecanismo intitulado licenciamento compulsório de patentes.

O licenciamento compulsório foi adotado na legislação nacional e está previsto no artigo 68 e seguintes da Lei Federal $n^{0}$ 9.279, de 14 de maio de 1996 e foi o mecanismo encontrado pelo legislador nacional para a consecução do interesse público. O licenciamento compulsório é o mecanismo pelo qual o Estado concede a um terceiro a utilização/fabricação de um determinado produto, sem o consentimento do titular da patente, mediante remuneração e por determinado período de tempo. Merece ser destacado que o titular da patente poderá buscar a proteção contra terceiros que a utilizem ou fabriquem seu produto sem a devida licença (CORREA, 2007, p. 193).

Os fatos que antecederam a edição da Lei de Propriedade Industrial têm grande relevância contextual para que se compreenda o instituto do licenciamento compulsório. No Brasil não havia a possibilidade de registro de patente de medicamentos pois havia expressa vedação no Código de Propriedade Industrial, Lei Federal n 5.772, de 21 de dezembro de 1971 (revogada):

“Art. $9^{\circ}$ - Não são privilegiáveis:

c) as substâncias, matérias, misturas ou produtos alimentícios, químico-farmacêuticos e medicamentos, de qualquer espécie, bem como os respectivos processos de obtenção ou modificação;

..."

A questão foi submetida ao Poder Judiciário, onde o Supremo Tribunal Federal analisou a constitucionalidade da vedação legal de patente de medicamentos e concluiu pela sua constitucionalidade ${ }^{8}$.

\footnotetext{
${ }^{8}$ R.E. $n^{\circ}$ 94.468-1-RJ, 1a Turma do STF, julgado em 13/04/1982, Rel. Ministro Néri da Silveira, D.J. 15.06.1984, p. 09793: "O legislador ordinário pode definir o que não é patenteável, seguindo critérios técnicos. Não dispôs o legislador ordinário em afronta ao espírito do dispositivo constitucional referido quando, no art. 9. ${ }^{\circ}$, 'c', da Lei 5.772/71s vedou a privilegiabilidade quanto às substâncias, matérias, misturas ou produtos alimentícios, químico-farmacêuticos e medicamentos de qualquer espécie, bem como aos respectivos processos de obtenção ou modificação. Recurso extraordinário não conhecido".
} 
Assim, os interesses das empresas transnacionais e multinacionais dos fabricantes de medicamentos estavam em risco, razão pela qual houve forte pressão destas empresas, principalmente da indústria farmacêutica norte americana para a extensão da proteção das patentes. Assim, o Brasil sofreu pressões comerciais bem como teve minada gradativamente sua posição de não de não conceder patentes a medicamentos em virtude de outros países como Argentina, Canadá, México, Chile, Espanha, Finlândia e Coréia do Sul adotaram a proteção a patente de medicamentos (OLIVEIRA, 2000, p. 131-132).

Portanto, no Governo do Presidente Fernando Collor de Melo, foi apresentado o Projeto de Lei ${ }^{0}$ 824/91 que teve diversas emendas e como forma de alinhar ao patamar mínimo de proteção prevista no TRIPS, desaguaram na Lei Federal n 9.279 , de 14 de maio de 1996, conhecida como Lei de Propriedade Industrial.

Assim, a nova Lei acabou por ceder aos interesses capitalistas e como bem observa o professor Ubirajara Mach de Oliveira, retirou a possibilidade de desapropriação que havia no artigo 39 da Lei $n^{\circ}$ 5.772/71 com fundamento no interesse e na segurança nacional (OLIVEIRA, $166,2000)$.

Mas a Lei Federal n ${ }^{0}$ 9.279/96 trouxe um mecanismo de exceção para não ficar refém do detentor da patente no que tange ao fornecimento e aos preços praticados pelo mesmo ou seu licenciado: o licenciamento compulsório. Assim, como se trata de medida de exceção os requisitos para que se falar em licenciamento compulsório devem estar presentes. Estes limites são traçados pelo artigo 68 da referida Lei:

"Art. 68. O titular ficará sujeito a ter a patente licenciada compulsoriamente se exercer os direitos dela decorrentes de forma abusiva, ou por meio dela praticar abuso de poder econômico, comprovado nos termos da lei, por decisão administrativa ou judicial”.

Mas não só o aspecto econômico foi lembrado na questão do licenciamento compulsório, pois o dispositivo acima visa coibir práticas abusivas de preços comercializados ao consumidor, mas também as questões de interesse social, como o caso do medicamento que será estudado adiante. Assim, dispõe o artigo 71 da Lei nº 9.279/96:

"Art. 71. Nos casos de emergência nacional ou interesse público, declarados em ato do Poder Executivo Federal, desde que o titular da patente ou seu licenciado não atenda a essa necessidade, poderá ser concedida, de ofício, licença compulsória, temporária e não exclusiva, para a exploração da patente, sem prejuízo dos direitos do respectivo titular. 
Parágrafo único. $\mathrm{O}$ ato de concessão da licença estabelecerá seu prazo de vigência e a possibilidade de prorrogação".

Ante o conceito aberto do que venha a ser emergência nacional ou interesse público, em 06 de outubro de 1999 foi publicado o Decreto $\mathrm{n}^{0} 3.201$, assinado pelo então Presidente Fernando Henrique Cardoso, que visava regulamentar o referido artigo 71 e disciplinar a utilização do licenciamento compulsório de ofício e os limites na emergência nacional e interesse público, que assim dispõe em seu artigo $2^{\circ}$ :

“Art. $2^{\circ}$ - Poderá ser concedida, de ofício, licença compulsória de patente, nos casos de emergência nacional ou interesse público, neste último caso somente para uso não comercial, desde que assim declarados pelo Poder Público, quando constatado que o titular da patente, diretamente ou através de seu licenciado, não atende a estas necessidades.

$\S 1^{\text {o }}$ Entende-se por emergência nacional o iminente perigo público, ainda que apenas em parte do território nacional.

$\S 2^{\circ}$ Consideram-se de interesse público os fatos relacionados, dentre outros, à saúde pública, à nutrição, à defesa do meio ambiente, bem como aqueles de primordial importância para o desenvolvimento tecnológico ou sócio-econômico do País".

Mas o caminho para se chegar a este decreto regulamentador foi árduo, na medida em que no ano de 1996, além da previsão do licenciamento compulsório, na Lei de Propriedade Industrial, foi promulgada a Lei Federal $n^{\circ}$ 9.313, de 13 de novembro de 1996, que trouxe os limites do licenciamento compulsório, pelo prazo de cinco anos, podendo ser prorrogado por até igual período com a finalidade de atender o Programa Nacional de DST/Aids. A mesma lei definiu a remuneração do titular da patente, consistente em um inteiro e cinco décimos por cento sobre o custo do medicamento produzido e acabado pelo Ministério da Saúde ou o preço do medicamento que lhe for entregue. Assim caberá ao Instituto Nacional de Propriedade Industrial efetuar o arbitramento desta remuneração.

E na prática, já foi efetuada a utilização deste instituto? Sim. O caso mais emblemático envolvendo o Brasil sobre este tema foi em relação ao antirretroviral EFAVIRENZ, do laboratório Merck, Sharp \& Dohme, medicamento utilizado no tratamento das pessoas infectadas com o vírus da AIDS (Síndrome da Deficiência Imunológica Adquirida).

O Estado Brasileiro, que é signatário da Declaração Universal dos Direitos Humanos, assumiu na Constituição de 1988 o dever de assegurar o direto a saúde, sendo este um direito social (art. $6^{\circ}, 196$ e 200 da Constituição Federal), que teve também estas disposições reiteradas 
na Lei Federal nº 8.080, de 19 de setembro de 1990 (Lei Orgânica da Saúde), onde a "saúde é entendida como um estado harmônico entre as dimensões física, mental e social do ser humano" (CARNEIRO, 2002, p. 23).

Vale lembrar que a AIDS já foi tratada como uma doença que era direcionada apenas a grupos de risco e os seus portadores foram alvo de grande discriminação. Os primeiros medicamentos eram excessivamente caros e pouco eficazes. Com o surgimento dos antirretrovirais houve uma significativa melhora na qualidade de vida dos doentes de AIDS. Todavia, este tipo de medicamento era muito caro para a maior parte dos doentes e muitas vezes inacessível.

A medida adotada pelo Estado Brasileiro para dar efetividade ao direito a saúde previsto nos artigos $5^{\circ}$ e $6^{\circ}$ da Lei Federal n ${ }^{\circ} 8.080 / 90$ através do Sistema único de Saúde (SUS) nos casos de fornecimento de medicamentos gratuitos para o tratamento foi a edição Lei Federal 9.313 de 11 de novembro de 1996, conhecida como Lei Sarney (CARNEIRO, 2002, p. 24).

Não obstante a legislação, o Brasil conta com "Plano Estratégico Programa Nacional de DST e AIDS" editado em 2005 e conta como Marco referencial: "Um aspecto central da estratégia do governo é a necessidade de garantir a disponibilidade de medicamentos e de outros insumos médicos a preços acessíveis, em face da dependência exclusiva do mercado brasileiro aos fornecedores internacionais de matérias-primas e de alguns bens necessários"

Assim, o Estado passa a agir de forma mais efetiva para assegurar um mínimo de dignidade das pessoas acometidas com a doença e também com fortes campanhas educativas e anti-discriminatórias.

Como o Estado Brasileiro assume esta obrigação de dar o mínimo de dignidade também com o fornecimento de medicamentos, teve de negociar diretamente o principal antirretroviral EFAVIRENZ, do laboratório Merck, Sharp \& Dohme, detentora da patente. Todavia estas negociações de valores do custo do medicamento estavam truncadas, uma vez que o valor era maior que os preços praticados em outros países. O então Ministro da Saúde, José Gomes Temporão, em assinou a Portaria $n^{\circ}$ 866, de 24 de abril de 2007, onde declarou de interesse público do referido medicamento com finalidade de licenciamento compulsório para uso não comercial.

O que levou o Brasil a adotar esta postura foi o fato do fabricante praticar uma política de preços muito maior daquela que era praticada com a Tailândia, e o fracasso das negociações

\footnotetext{
9 http://bvsms.saude.gov.br/bvs/publicacoes/plano_estrategico.pdf (acessado em 10/06/2016).
} 
entre o Governo Nacional e a Fabricante. O custo de cada pílula para o mercado nacional era de US\$ 1,59 (um dólar e cinquenta e nove centavos norte americanos) na medida em que para o mercado Tailandês era de US\$ 0,65 (sessenta e cinco centavos de dólar norte americano) ${ }^{10}$.

Importante salientar que ainda que tenha um cunho econômico, o fundamento para o licenciamento compulsório no caso acima apresentado é o interesse público, já que não se discutia a negociação de valores do produto ao consumidor final, pois neste último caso aplicarse-ia o disposto no inciso II do artigo 68 da Lei de Propriedade Industrial.

O produto era um dos itens do Estado Brasileiro garantir ao doente de AIDS o mínimo de dignidade, disponibilizado pelo Sistema Único de Saúde de forma gratuita, razão pela qual é aplicável o disposto no artigo 71 da Lei ${ }^{0}$ 9.279/96.

Assim, o licenciamento compulsório passou a ser também uma ferramenta de negociação, que foi utilizada em outras oportunidades: 1) O medicamento Nelfinadir, fabricado pela empresa Roche, reduziu o preço em 40\% (quarenta por cento) após anúncio do Ministro da Saúde José Serra do licenciamento compulsório, em agosto de $2001^{11}$; 2) A redução dos preços dos medicamentos Nelfinavir, Lopinavir, Efavirenz, Tenofovir e Atazanavir, em janeiro de 2004, após o Ministro da Saúde Humberto Costa anunciar que o Governo Brasileiro poderia adotar medida para produção do Nelfinavir, em dezembro de $2013^{12}$; 3 ) o medicamento Kaletra (Lopinavir + Ritonavir), da empresa Abbott teve decretado o interesse público, pelo então presidente Luiz Inácio Lula da Silva, em junho de $2005^{13}$.

O licenciamento compulsório do medicamento Efavirenz foi materializado através do Decreto $n^{0} 6.108$ de 04 de maio de 2.007, assinada pelo Presidente Luiz Inácio Lula da Silva que "concede licenciamento compulsório, por interesse público, de patentes referentes ao Efavirenz, para fins de uso público não-comercial".

No referido decreto foi estabelecida a remuneração do detentor da patente que foi fixada em um inteiro e cinco décimos por cento sobre o custo do medicamento produzido e acabado pelo Ministério da Saúde ou o preço do medicamento que lhe for entregue. Assim,

\footnotetext{
10 http://www.reporterdiario.com.br/noticia/3767/temporao-pede-quebra-de-patente-de-remedio-anti-aids/ (acessado em 10/06/2016).

11 http://www.bbc.com/portuguese/noticias/2001/010823_aidsbrasil.shtml

$12 \mathrm{http}: / /$ politica.estadao.com.br/noticias/geral,governo-ameaca-nacionalizar-producao-de-remedio-daroche, $20031207 \mathrm{p} 36658$

13 http://www.bbc.com/portuguese/reporterbbc/story/2005/07/050709_patentekaletracg.shtml
} 
resta claro que o licenciamento compulsório não se trata de expropriação, mas uma forma prática de exercer a função social da propriedade.

Embora não seja objetivo deste trabalho deve lembrar-se o que escreveu-se em outra oportunidade (TEJERINA VELÁZQUEZ, Victor Hugo; COLLA DE OLIVEIRA, Michele Cristina Souza, 2016, p. 77-81):

A mensuração do custo real de um medicamento pressupõe a combinação de uma séria de fatores econômicos e políticos analisados de modo breve no presente trabalho. Todavia, segundo RATHI ${ }^{14}$, podemos explorar a temática por intermédio da divisão dos gastos anuais com pesquisa e desenvolvimento pelo número de drogas produzidas no referido período:

Encontrar o custo real de um medicamento é um exercício complexo e controverso. Todavia, uma maneira aceitável para mensurar os custos reais é dividir os gastos em P \& D de empresas farmacêuticas pelo número de novas drogas produzidas anualmente. A despeito das diferenças terminológicas do que seriam os gastos em P \& D, o custo de uma nova droga nos Estados Unidos da América está entre $\$ 1$ bilhão a US \$ 5 bilhões. ${ }^{15}$ (Why there may be fewer truly new drugs hitting the Market. Disponível em: <http://theconversation.com/why-there-may-be-fewer-truly-new-drugshitting-the-market-22315>. Acesso em: 24 Jul. 2014, tradução nossa)

A partir da proposta de RATHI ${ }^{16}$ para apuração do custo real de um medicamento, com propósito comparativo, colacionamos o gráfico de produtividade da indústria farmacêutica americana, de 1996 a $2013^{17}$ :

\footnotetext{
14 "Finding the true cost of a new drug is a complex and controversial exercise. However, one acceptable way to calculate it is to divide total R\&D spend of pharma companies by the number of new drugs produced. Because of differences in agreeing what constitutes $R \& D$ spend, even this measure produces only a range - the cost of a new drug is somewhere between US\$1 billion and US\$5 billion." RATHI, Akshat. Why there may be fewer truly new drugs hitting the Market. Disponível em: <http://theconversation.com/ why-there-may-be-fewer-truly-new-drugs-hitting-the-market-22315>. Acesso em: 24 Jul. 2014.

${ }^{15}$ Idem.

16 "Finding the true cost of a new drug is a complex and controversial exercise. However, one acceptable way to calculate it is to divide total R\&D spend of pharma companies by the number of new drugs produced. Because of differences in agreeing what constitutes $R \& D$ spend, even this measure produces only a range - the cost of a new drug is somewhere between US\$1 billion and US\$5 billion." RATHI, Akshat. Why there may be fewer truly new drugs hitting the Market. Disponível em: <http://theconversation.com/why-there-may-be-fewer-truly-newdrugs-hitting-the-market-22315>. Acesso em: 24 Jul. 2014.

17 Idem.
} 


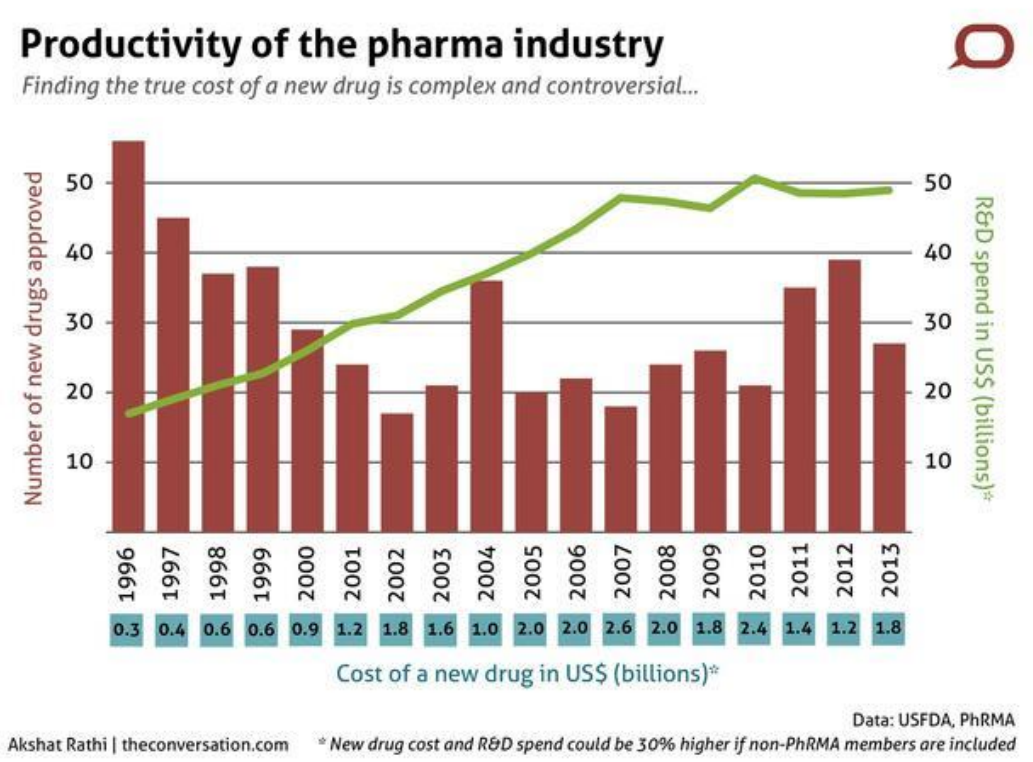

Gráfico de produtividade da indústria farmacêutica americana, 1996 a 2013.

Diante de tal panorama, faz-se necessária a análise comparativa acima, cujo enfoque está no percentual de investimento em $\mathrm{P} \& \mathrm{D}$ em relação à receita bruta de vendas.

\section{País x Investimento em P\&D (2012)}
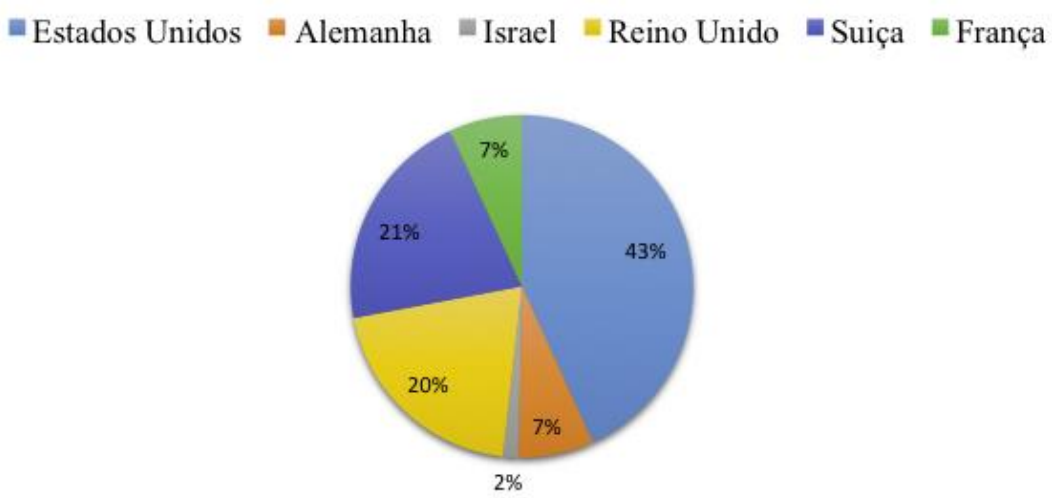

\section{Gráfico de investimento em P\&D}

Mencionava-se também que:

Primeiramente, elenca-se, para o ano de 2013, as quinze principais multinacionais do setor farmacêuticas, as quais são detentoras das patentes dos principais medicamentos utilizados em países em desenvolvimento, em especial dos antirretrovirais. 


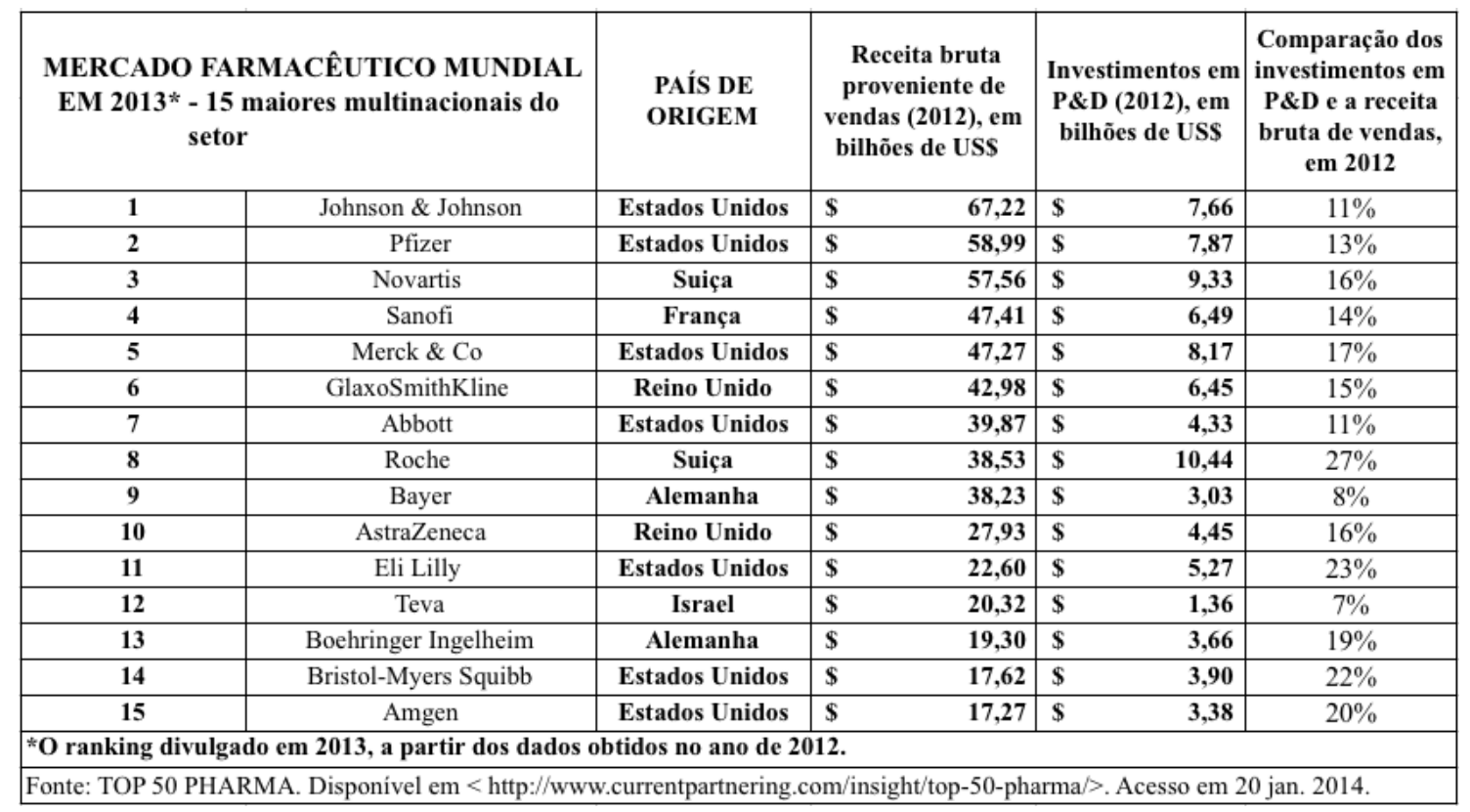

Tabela 1 - Mercado farmacêutico mundial em 2013 e investimentos em P\&D

Por exemplo, a Merck \& Co, quinta colocada na escala acima, patenteou no Brasil o medicamento EFAVIRENZ ${ }^{18}$, cujo licenciamento compulsório foi promovido administrativamente pelo governo brasileiro, mediante o decreto $\mathrm{n}^{\circ} 6.108$, de 4 de maio de 2007.

Tratando-se em bilhões de dólares, destaca-se a relação entre a receita bruta proveniente das vendas de medicamentos e os investimentos em P\&D, para o ano de 2012. A razão entre investimentos em $P \& D$ e a receita bruta indicam a distorção das afirmações de que o licenciamento compulsório seria obstáculo ao retorno dos investimentos em $\mathrm{P} \& \mathrm{D}$, ou mesmo, constituiria um entrave à inovação ${ }^{19}$.

Em termos de domínio do mercado farmacêutico, considerando-se, a título exemplificativo, o ano de 2013 e as receitas e investimentos de 2012, os Estados Unidos da América, no grupo das 15 gigantes farmacêuticas ${ }^{20}$, são sede de 07 - Johnson \& Johnson, Pfizer, Merck \& Co, Abbott, Eli Lilly, Bristol-Myers Squibb e Amgen -, representando uma concentração de mercado de, aproximadamente, $46 \%$, conforme representado no gráfico a seguir:

\footnotetext{
${ }^{18}$ Patentes registradas no INPI sob os números 1100250-6 e 9608839-7.

${ }^{19}$ MORAIS, Rafael Pinho Senra. Textos para discussão: modelos de fomento e P\&D em farmacêuticos e benchmarking internacional. Instituto de Pesquisa Econômica Aplicada. Rio de Janeiro: Ipea, 2013. Disponível em < http://www.ipea.gov.br/portal/images/stories/PDFs/TDs/td_1825.pdf >. Acesso em 18 jan. 2014.

${ }^{20}$ TOP 50 PHARMA. Disponível em < http://www.currentpartnering.com/insight/top-50-pharma/>. Acesso em 20 jan. 2014.
} 


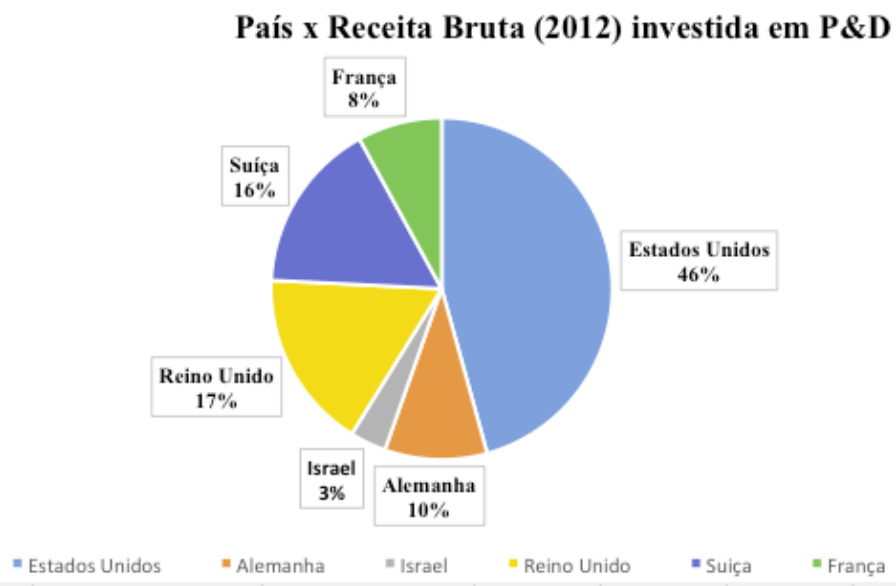

Comparação entre a receita bruta anual de cada país e os investimentos em P\&D

E, atualmente, as sete maiores empresas do setor farmacêuticas norte-americano possuem filiais no Brasil. Em uma análise perfunctória, a concentração de empresas norteamericanas no Brasil, segundo QUINTANEIRO ${ }^{21}$, possui uma justificativa histórica, pois:

O mercado sul-americano de químicos e remédios era, no início do século XX, dominado pela Alemanha, seguida pela França e Inglaterra (Thayer, 1914). Mas, por volta de 1914, os Estados Unidos já disputavam a terceira colocação nas vendas para o Brasil. Entre 1910 e 1912, do total de medicamentos importados na forma de cápsulas, comprimidos e glóbulos, $65 \%$ ou mais eram de origem norte-americana.

A potencialidade do mercado farmacêutico brasileiro foi notada pelas indústrias norteamericanas, nos idos de 1935, no início dos conflitos da Segunda Guerra Mundial, ocasião em que os Estados Unidos, segundo QUINTANEIRO ${ }^{22}$, despenderam “(...)um considerável esforço para desalojar, do lucrativo mercado farmacêutico do Brasil (...), a indústria alemã (...), tratando de promover sua substituição pelo capital privado norte-americano ou por interesses aliados locais".

No Brasil, o processo de internacionalização do setor farmacêutico ocorrido entre 1945 e 1969, segundo CAVALHEIRO ${ }^{23}$, redundou na concentração de empresas farmacêuticas norte-americanas no mercado brasileiro.

\footnotetext{
${ }^{21}$ QUINTANEIRO, Tania. O mercado farmacêutico brasileiro e o esforço de guerra norte-americano. Revista Estudos Históricos, Brasil, 1, out. 2002. Disponível em: http://bibliotecadigital.fgv.br/ojs/index.php/reh/article/view/2155/1294. Acesso em: 24 Jul. 2014.

${ }^{22}$ Idem.

${ }^{23}$ CAVALHEIRO, Rodrigo da Costa Ratto. 0 monopólio e as multinacionais farmacêuticas. Itu: Ottoni Editora, 2006. p.232.
} 
Em 07 de maio de 2012 houve a prorrogação do prazo do licenciamento compulsório por mais cinco anos através do Decreto $\mathrm{n}^{0} 7723$, mantendo-se o fundamento de interesse público ${ }^{24}$.

E este licenciamento está de acordo apenas com a legislação nacional ou também encontra sustentáculo em Convenções e Tratados internacionais? O artigo 21 do TRIPS assim dispõe:

"Os Membros poderão determinar as condições para a concessão de licenças de uso e cessão de marcas, no entendimento de que não serão permitidas licenças compulsórias e que o titular de uma marca registrada terá o direito de ceder a marca, com ou sem a transferência do negócio ao qual a marca pertença."

Assim, merece ressaltar que a medida adotada pelo Governo Brasileiro, além de estar devidamente fundamentada em relevante interesse público como forma de fomentar o direito a saúde e resguardar o direito a vida, tem base legal reconhecida internacionalmente para promover o licenciamento compulsório do medicamento ora discutido.

O programa nacional de combate a AIDS conta com esta importante ferramenta que é o licenciamento compulsório, com objetivo de melhorar a qualidade de vida dos doentes e tem repercussão nacional e internacional, uma vez que o programa brasileiro é referência para outros países e em consonância com o TRIPs, de forma a manter a segurança das relações de propriedade industrial no mundo inteiro (BEZERRA, 2010, p.187).

Através deste estudo pudemos concluir que existe a proteção à propriedade intelectual, mas a mesma deverá sempre atender a sua função social, pois a preservação a vida, saúde e dignidade da pessoa humana devem sempre prevalecer.

O instituto de licenciamento compulsório serviu e serve como forma não apenas de buscar justiça na prática de preços, de forma a fomentar as necessidades de nosso País, mas também atender as necessidades sociais, observando-se que para a utilização do licenciamento compulsório, sempre devem estar presentes os requisitos, não podendo utilizar deste instituto de forma leviana, sob pena de desafiar não apenas a legislação pátria, mas também os princípios de segurança aos inventores, detentores de patentes e seus licenciados, inseridos no acordo TRIPs.

\footnotetext{
24 http://www.brasil.gov.br/saude/2012/05/brasil-renova-licenciamento-compulsorio-de-antirretroviral-usado-no-tratamentoda-aids
} 
Assim, verifica-se que a medida governamental buscou a compatibilização do direito a propriedade, com sua função social, com os direitos fundamentais que a Constituição buscou resguardar: a vida, saúde e dignidade da pessoa humana.

O princípio da função social da propriedade privada é aplicável à propriedade intelectual na medida em que deve atender uma finalidade social de cada país, de modo que também representa um dever para o seu titular, que deverá efetuar a utilização de seu direito em consonância dom o bem-estar social (BEZERRA, 2010, p. 92).

\section{CONSIDERAÇÕES FINAIS}

A proteção da propriedade industrial sobre os medicamentos modificou radicalmente o contexto brasileiro, pois o interesse público, que antes era sobre qualquer medicamento, hoje não mais o é. Assim, resta evidente que os interesses das indústrias farmacêuticas e seus licenciados está suficientemente garantido, pois ainda que haja o licenciamento compulsório, para que se utilize deste instituto, sempre haverá a necessidade de preenchimento de requisitos, e será de forma temporária.

A legislação em vigor buscou harmonizar o mínimo entre a função social da propriedade e o instituto do licenciamento compulsório. Este último, servirá como medida excepcional, nas hipóteses em que houver a prática de monopólio, abuso de direito ou ineficiência da atuação do detentor da patente ou seu licenciado frente ao mercado e, ainda, nos casos de relevante interesse público, como foi o caso do medicamento antirretroviral ora estudado.

Portanto, não há de se falar em desrespeito aos direitos dos titulares da patente, uma vez que o licenciamento compulsório encontra fundamento não apenas na legislação pátria, mas também no acordo internacional TRIPs, devendo ser observadas as condições específicas para a concessão desta modalidade de licenciamento, compatibilizando-se, assim a criação do intelecto humano, bem como investimento de tempo e recursos financeiros e de toda ordem. Assim, deverá haver a análise crítica, sendo a mesma pautada pelo princípio da proporcionalidade e razoabilidade a fim de que interesse público não seja afastado, garantindose assim o função social da propriedade intelectual.

A legislação, todavia, não traz outras medidas protetivas no que diz respeito a indústria nacional e lamentavelmente, no setor de medicamentos ainda ficamos à mercê dos 
grandes conglomerados farmacêuticos. Assim, para que haja efetiva possibilidade de poder se impor no mercado globalizado é imprescindível o investimento interno em Pesquisa, Desenvolvimento e Inovação a fim de que o Brasil possa conquistar um lugar de destaque como país tecnologicamente desenvolvido.

\section{REFERÊNCIAS}

BRASIL. BRASIL, 1988. Constituição (1988). Disponível em < http://www.planalto.gov.br/ccivil_03/constituicao/constituicao.htm > (Acesso em 09 de junho de 2016).

BRASIL. Decreto n ${ }^{\circ} 3.201$, de 6 de outubro de 1999. DF, Presidência da República, 1999. Disponível em < http://www.planalto.gov.br>. Acesso em 09 de junho de 2016).

BRASIL. Lei Federal n ${ }^{\circ}$ 5.772, de 21 de dezembro de 1971 (revogada). DF, Congresso Nacional, 1990. Disponível em < http://www.planalto.gov.br>. Acesso em 09 de junho de 2016).

BRASIL. Lei Federal n ${ }^{\circ}$ 8.080, de 19 de setembro de 1990. DF, Congresso Nacional, 1990. Disponível em < http://www.planalto.gov.br>. Acesso em 09 de junho de 2016).

BRASIL. Lei Federal n 9.279, de 14 de maio de 1996. DF, Congresso Nacional, 1996. Disponível em < http://www.planalto.gov.br>. Acesso em 09 de junho de 2016).

BRASIL. Lei Federal n ${ }^{\circ}$ 9.313, de 13 de novembro de 1996. DF, Congresso Nacional, 1996. Disponível em < http://www.planalto.gov.br>. Acesso em 09 de junho de 2016).

BEZERRA, Matheus Ferreira. Patente de Medicamentos: Quebra de Patente como Instrumento de Realização de Direitos. Curitiba: Juruá: 2010.

CARNEIRO, Claudia Maria de Paula; PELEGRINO, Nelson. O outro como um semelhante: direitos humanos e aids. In CAMARA, Cristina; CARNEIRO, Claudia Maria de Paula (Coords). Brasília: Ministério da Saúde, 2002. 
CASTRO, Luiz Fernando Vallim de. Função Social da Propriedade Industrial. In TEJERINA VELÁZQUEZ, Victor Hugo; GONZALEZ, Everaldo Tadeu Quilici; COLLA DE OLIVEIRA, Michele Cristina Souza Achcar (Coords). Direitos Humanos, Propriedade Intelectual e Sustentabilidade. Curitiba: Juruá, 2016. p. 135-156.

CAVALHEIRO, Rodrigo da Costa Ratto. O monopólio e as multinacionais farmacêuticas. Itu: Ottoni Editora, 2006. p.232.

CHALLONER, Jack. 1001 Invenções que mudaram o mundo. Rio de Janeiro: Sextante, 2010.

COELHO, Fábio Ulhôa. Manual de Direito Comercial. $8^{\mathrm{a}}$ ed. São Paulo: Saraiva, 1997.

COMPARATO, Fabio Konder. Função Social dos bens de produção. Revista de Direito Mercantil. V.63, São Paulo, 1986.

CORREA, Carlos M.. Propriedade Intelectual e Saúde Pública. Florianópolis: Fundação Boiteux. 2007.

DEL NERO, Patrícia Aurélia. Propriedade Intelectual: A tutela jurídica da biotecnologia. São Paulo: Revista dos Tribunais, 1998.

FERREIRA FILHO, Manoel Gonçalves. Curso de Direito Constitucional. $18^{\mathrm{a}}$ Ed. São Paulo, Saraiva 1990.

MORAIS, Rafael Pinho Senra. Textos para discussão: modelos de fomento e P\&D em farmacêuticos e benchmarking internacional. Instituto de Pesquisa Econômica Aplicada. Rio de Janeiro: $\quad$ Ipea, 2013. Disponível em http://www.ipea.gov.br/portal/images/stories/PDFs/TDs/td_1825.pdf >. Acesso em 18 jan. 2014. 
OLIVEIRA, Ubirajara Mach de. A Proteção Jurídica das Invenções de Medicamentos e de Gêneros Alimentícios. Porto Alegre: Síntese, 2000.

QUINTANEIRO, Tania. O mercado farmacêutico brasileiro e o esforço de guerra norteamericano. Revista Estudos Históricos, Brasil, 1, out. 2002. Disponível em: http://bibliotecadigital.fgv.br/ojs/index.php/reh/article/view/2155/1294. Acesso em: 24 Jul. 2014.

RATHI, Akshat. Why there may be fewer truly new drugs hitting the Market. Disponível em: <http://theconversation.com/

why-there-may-be-fewer-truly-new-drugs-hitting-the-market-22315>. Acesso em: 24 Jul. 2014.

ROTHENBURG, Walter Claudius. Direitos Fundamentais. São Paulo: Método, 2014.

SILVA, José Afonso. Curso de Direito Constitucional Positivo. 19ª Ed. São Paulo: Malheiros, 2000.

TEJERINA VELÁZQUEZ, Victor Hugo; COLLA DE OLIVEIRA, Michele Cristina Souza. Breve Análise dos Custos dos Medicamentos no Brasil. In: TEJERINA VELÁZQUEZ, Victor Hugo; GONZALEZ, Everaldo Tadeu Q.; COLLA DE OLIVEIRA, Michele Cristina Souza.(Cords). Direitos Humanos, Propriedade Intelectual e Sustentabilidade. Curitiba: Juruá, 2016.

TOP 50 PHARMA. Disponível em < http://www.currentpartnering.com/insight/top-50pharma/>. Acesso em 20 jan. 2014.

VIZZOTTO, Alberto. A função Social das Patentes sobre Medicamentos. São Paulo: LCTE Editora, 2010.

ZANIN NETO, Armando. TEJERINA VELÁZQUEZ, Victor Hugo. Função Social da Propriedade Intelectual e o Desenvolvimento Social. TEJERINA VELÁZQUEZ, Victor Hugo; GONZALEZ, Everaldo Tadeu Quilici (Coords). In Direitos Humanos, Propriedade Intelectual e Desenvolvimento. Curitiba: Juruá, 2012. p. 245-263. 